\title{
THE RELATIONSHIP BETWEEN THE DEPTH OF THE CURVE OF SPEE AND DIFFERENT TYPES OF MALOCCLUSION.
}

\author{
Mai H. Aboulfotouh ${ }^{1}$, Mostafa M. El-Dawlatly ${ }^{1}$
}

\section{INTRODUCTION}

The curve of Spee was first described by Graf Von Spee as an anatomic curvature constituting part of a cylinder passing tangential to the incisal edges of the lower incisors, the mandibular second molar and the mandibular condyle. The center of this cylinder lies in the mid-orbital plane with a radius of 6.6-7 $\mathrm{cm}(1)$. From the clinical aspect, the curve of Spee is determined by the distal marginal ridges of posterior teeth together with the incisal edges of the lower incisors.

The significance of the curve of Spee still remains unclear. However, its importance in increasing the masticatory efficiency and the distribution of the occlusal forces has been reported in previous research.(2-4)

Several factors have been reported for affecting the development of the curve of Spee including the mandibular incisor proclination (5-7), lower arch circumference $(7,8)$ incisor overbite $(9,10)$ as well as craniofacial morphology $(11,12)$.

Andrews(13) described the six keys of occlusion and stated that the curve of Spee ranged from flat to mild in individuals with normal occlusion. A deep curve of Spee has been correlated with deep bite malocclusions. Therefore, leveling the curve of Spee is considered an integral part of the treatment of most orthodontic cases. This can be achieved through several modalities including incisor intrusion or molar extrusion(14). Understanding the relationship between the different types of malocclusion and the curve of Spee will allow better treatment of such orthodontic cases. Therefore, this study aimed to determine the depth of the curve of Spee in different types of malocclusion.

\section{MATERIALS AND METHODS}

This study was designed as a retrospective cross-sectional study on records of orthodontic patients obtained from the outpatient clinic, Department of Orthodontics, Faculty of Dentistry, Cairo University. Due to the retrospective nature of the study, as well as being carried on dental models, no approval of the ethics committee was sought. Dental models of one hundred and twenty patients (47

[1] Lecturer- Department of Orthodontics- Faculty of Dentistry -Cairo University.

Morth- RCSED

[1] Lecturer- Department of Orthodontics- Faculty of Dentistry -Cairo University.

Morth- RCSED

Orthodontic Society 
males and 73 females with age range between 14- 25years) were selected and included in the study. All patients fulfilled the following inclusion criteria: healthy subjects having complete set of permanent dentition including fully erupted second permanent molars. Except for the third molars, no other maxillary or mandibular teeth were absent. None of the patients had previous orthodontic treatment. All patients were free of any craniofacial disorder, any tooth attrition or wear. The casts were divided into 4 equal groups of 30 casts each according to the type of malocclusion as defined by the British standards of classification.

Group 1 class I malocclusion

Group 2 class II div 1 malocclusion

Group 3 class II div 2 malocclusion

Group 4 class III malocclusion

The dental models were scanned using 3-dimensional desktop laser Scanner (3Shape, Copenhagen, Denmark). The digital models were then analyzed using the 3Shape Orthoanalyzer 2019 software and the curve of Spee was measured according to the method advocated by Braun et al.(10). It was measured as the perpendicular distance between the deepest cusp tip and a horizontal reference plane that was laid between the lower central incisors and the distobuccal cusp of the mandibular second molars as shown in figure (1). The measurement was made on the right and left sides of the dental arch and the mean value of these two measurements was used as the depth of the curve of Spee.

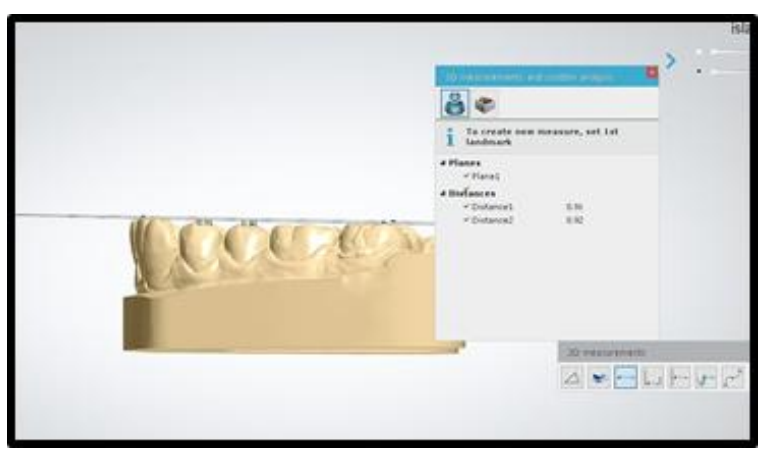

Figure (1): A screenshot of the Orthoanalyser Software showing measurement of the curve of Spee

\section{STATISTICAL ANALYSIS}

Statistical analysis was performed with SPSS 16 ( ) (Statistical Package for Scientific Studies), Graph pad prism \& windows excel. Data were presented as mean \&standard deviation.

One Way Repetitive ANOVA was performed to compare between the four groups and find if there was a significant difference between them. Significance level was set at $\mathrm{P} \leq 0.05$.

\section{RESULTS}

Class II div 2 cases revealed the highest mean $(2.95 \mathrm{~mm} \pm 0.58)$ indicating the deepest curve of Spee, followed by class II div $1(2.49 \mathrm{~mm} \pm 0.64)$, then class I $(1.96 \mathrm{~mm} \pm$ $0.61)$, while the least was class III $(1.79 \mathrm{~mm} \pm$ 0.52 ) as presented in table (1) and figure (2).

One Way Repetitive ANOVA was performed to compare between four groups and revealed significant difference between them $(\mathrm{P}<0.05)$, followed by Tukey`s post hok 
test for multiple comparisons which revealed significant difference between means with different superscript letters as $\mathrm{P}<0.05$ as shown in table (1). Therefore, a significant difference was found between the depths of the curves of Spee when comparing between class I \& class II division 1malocclusion, class I \& class II division 2 malocclusion, class II division 1 \& class II division 2, class II division 1 \& class III malocclusion and between class II div 2 \& class III malocclusion. However, an insignificant difference was found between the depths of the curves of Spee between Class I and Class III malocclusion cases which was represented with the same superscript letters as $\mathrm{P}>0.05$ as shown in table(1) .

Table (1): Mean and standard deviation of curve of Spee depth in different types of malocclusion.

\begin{tabular}{|l|l|l|l|l|l|l|} 
& \multicolumn{1}{|c|}{ N } & \multicolumn{2}{c|}{ Min. Max } & \multicolumn{1}{l|}{ SD } & P value \\
\hline class I & 30 & 0.37 & 2.93 & $1.96^{\mathbf{a}}$ & 0.61 & \\
\hline $\begin{array}{l}\text { Class II } \\
\text { div1 }\end{array}$ & 30 & 1.13 & 3.85 & $2.49^{\mathbf{b}}$ & 0.64 & $<$ \\
\hline $\begin{array}{l}\text { class II } \\
\text { div2 }\end{array}$ & 30 & 2.08 & 4.25 & $2.95^{\mathbf{c}}$ & 0.58 & $0.001^{*}$ \\
\hline class II & 30 & 0.68 & 3.01 & $1.79^{\mathbf{a}}$ & 0.52 & \\
\hline
\end{tabular}

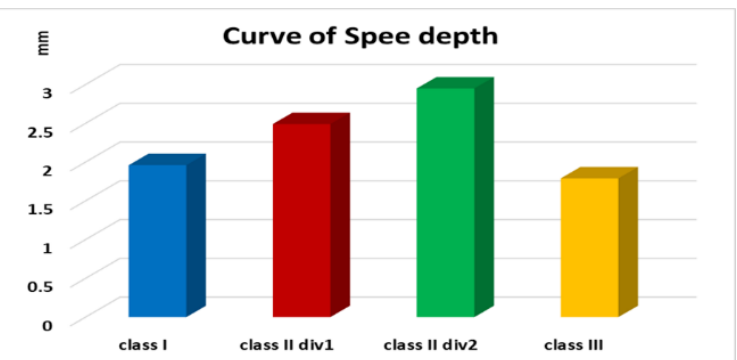

Figure (2): Bar chart showing the means of curve of Spee depths in different types of malocclusion.

\section{DISCUSSION}

Many of the orthodontic problems are associated with an increased curve of Spee and therefore, evaluation of the depth of the Curve of Spee plays a pivotal role in orthodontic diagnosis and treatment planning. Although there are different opinions about the development of the COS, it is important to know in which type of malocclusion this curve is more severe. Therefore, this study was performed to assess the relationship between different sagittal dental malocclusions and the depth of the curve of Spee.

Gender predilection has not been reported to affect the depth of the curve of Spee $(15,16)$. Therefore, no attempt was made to separate the sample according to sex in this study.

It has been claimed that the depth of the $\mathrm{COS}$ is stable throughout adolescence and into adulthood(15,17) Accordingly, adolescents and young adults with all teeth present except third molars were included in the study.

The patient's craniofacial morphology has been suggested to have little influence on the depth of the curve of Spee as reported by Kumar and Tamizharasi.(18) Therefore, patient selection was based primarily on dental malocclusion. Moreover, patients with any facial asymmetry or skeletal abnormalities were excluded from the study as not to affect the depth of the curve of Spee. 
In the current study, the Curve of Spee is determined by the distal marginal ridges of the mandibular second molars and the incisal edges of the central incisors. Reviewing the literature, many methods for calculating the depth of the curve of Spee have been adopted. Bishara et al.(17), used the average of the sum of the perpendicular distances to each cusp tip, while Braun et al.(10) and Braun and Schmidt(19) used the average of the sum of the maximum depth on both sides. However, these measurements were made on plaster models with a caliper. With the recent advances in the 3D technology, digitized study models of plaster casts are now available. Moreover, precise measurements can be now made using highly specialized software $(20,21)$. The accuracy and validity of measurements carried out on the 3D digitized models have been experimented in several studies(22-24). Considering the accuracy of the measured outcome together with the ease of use as well as the reduced time, digital models were used in this study.

Analyzing the results of the current study, the mean depth of the curve of Spee was greatest in the Class II division 2 malocclusion cases, followed by Class II Division 1, Class I, and then Class III, with the least depth. These results suggest that the depth of the curve of Spee in the mandibular arch is affected by the anteroposterior position of the mandibular incisors which in turn supports the evidence that the radius of the curve of Spee is shorter in subjects with Class II malocclusion(11). Those results were in alignment with findings of of Imtiaz et al.(25) and Shanon \& Nanda(26). On the contrary, a similar study by Veli et al.(27) reported higher means for the curve of Spee in class II division 1 than in division 2 cases. Other studies reported deeper curves of Spee in class II malocclusion followed by class I and then class III without taking into consideration any differences between divisions 1 and 2 of class II $(28,29)$.

Comparing the different types of malocclusion, a statistically significant difference between Class I malocclusion and each of Class II division 1 and Class II division 2 malocclusions was found in the current study. On the other hand, Braun and Schmidt(19) reported similar depths of the curves of Spee for those with Class I and Class II malocclusion. Moreover, Class II division 2 cases showed significantly deeper curve of Spee than Class II division 1 cases. This was in disagreement with the findings of Veli et al.(27) where no significant difference was found in the depth of the curve of Spee between both groups. Regarding the depths of the curve of Spee for class III malocclusion, no significant difference was found between class I and class III malocclusion. Similar findings were reported by Sayar \& Oktay(29) and Veli et al.(27). 
Treatment techniques to deal with exaggerated curves of Spee and the stability of those treatments are an all-time attraction for orthodontists worldwide (30). Our findings provide insight into the magnitude of the curve of Spee in different types of malocclusion.

\section{CONCLUSIONS:}

1. The depth of the curve of Spee was deepest in Class II division 2 malocclusion, followed by Class II division 1, Class I, and then Class III, which showed least depth of the curve of Spee.

2. There was a significant difference between class I and both divisions of class II malocclusion.

3. There was a significant difference between the depths of the curve of Spee in class II division 1 and Division 2 cases.

4. There was a significant difference between both divisions of class II and class III malocclusion.

5. There was NO significant difference between the depths of the curve of Spee between Class I and Class III malocclusion

\section{REFERENCES}

1. Spee FG, Biedenbach MA, Hotz M, Hitchcock HP. The Gliding Path of the Mandible along the Skull. J Am Dent Assoc. 1980;

2. Osborn JW. Relationship between the mandibular condyle and the occlusal plane during hominid evolution: Some of its effects on jaw mechanics. Am J Phys Anthropol. 1987

3. Kurusu A, Horiuchi M, Soma K. Relationship between occlusal force and mandibular condyle morphology. Angle Orthod. 2009;

4. Marshall SD, Caspersen M, Hardinger RR, Franciscus RG, Aquilino SA, Southard TE. Development of the curve of Spee. Am J Orthod Dentofac Orthop. 2008;

5. Pandis N, Polychronopoulou A, Sifakakis I, Makou M, Eliades T. Effects of levelling of the curve of Spee on the proclination of mandibular incisors and expansion of dental arches: a prospective clinical trial. Aust Orthod J. 2010;

6. Woods M. A reassessment of space requirements for lower arch leveling. J Clin Orthod. 1986;

7. Chung TS, Sadowsky PL, Wallace DD, McCutcheon MJ. A three-dimensional analysis of mandibular arch changes following curve of Spee leveling in nonextraction orthodontic treatment. Int $\mathbf{J}$ Adult Orthodon Orthognath Surg. 1997;

8. Germane N, Staggers JA, Rubenstein L, Revere JT. Arch length considerations due to the curve of Spee: A mathematical model. Am J Orthod Dentofac Orthop. 1992;

9. Trouten JC, Enlow DH, Rabine M, Phelps AE, Swedlow D. Morphologic factors in open bite and deep bite. Angle Orthod. 
1983;

10. Braun S, Hnat WP, Johnson BE. The curve of Spee revisited. Am J Orthod Dentofacial Orthop. 1996;

11. Orthlieb JD. The curve of spee: Understanding the sagittal organization of mandibular teeth. Cranio. 1997;

12. Farella M, Michelotti A, Van Eijden TMGJ, Martina R. The curve of Spee and craniofacial morphology: A multiple regression analysis. Eur J Oral Sci. 2002;

13. Andrews LF. The six keys to normal occlusion. Am J Orthod. 1972;

14. AlQabandi AK, Sadowsky C, BeGole EA. A comparison of the effects of rectangular and round arch wires in leveling the curve of Spee. Am J Orthod Dentofacial Orthop. 1999;

15. Carter GA, McNamara JA. Longitudinal dental arch changes in adults. Am J Orthod Dentofacial Orthop. 1998;

16. Xu H, Suzuki T, Muronoi M, Ooya K. An evaluation of the curve of Spee in the maxilla and mandible of human permanent healthy dentitions. J Prosthet Dent. 2004;

17. Bishara SE, Jakobsen JR, Treder JE, Stasl MJ. Changes in the maxillary and mandibular tooth size-arch length relationship from early adolescence to early adulthood. A longitudinal study. Am J Orthod Dentofac Orthop. 1989;

18. Tamizharasi S, Senthil Kumar K. Significance of curve of Spee: An orthodontic review. J Pharm Bioallied Sci. 2012;
19. Braun ML, Schmidt WG. A cephalometric appraisal of the curve of spee in Class I and Class II, Division 1 occlusions for males and females. Am J Orthod. 1956;

20. Kuroda T, Motohashi N, Tominaga R, Iwata K. Three-dimensional dental cast analyzing system using laser scanning. Am J Orthod Dentofacial Orthop. 1996;

21. Sohmura T, Kojima T, Wakabayashi K, Takahashi J. Use of an ultrahigh-speed laser scanner for constructing three-dimensional shapes of dentition and occlusion. J Prosthet Dent. 2000;

22. Gracco A, Buranello M, Cozzani M, Siciliani G. Digital and plaster models: a comparison of measurements and times. Prog Orthod. 2007;

23. Sousa MVS, Vasconcelos EC, Janson G, Garib D, Pinzan A. Accuracy and reproducibility of 3-dimensional digital model measurements. Am J Orthod Dentofac Orthop. 2012;

24. Quimby ML, Vig KWL, Rashid RG, Firestone AR. The accuracy and reliability of measurements made on computer-based digital models. Angle Orthod. 2004;

25. Ahmed I, Nazir R, Gul-e-Erum, Ahsan T. Influence of malocclusion on the depth of curve of Spee. J Pak Med Assoc. 2011;

26. Shannon KR, Nanda RS. Changes in the curve of Spee with treatment and at 2 years posttreatment. Am J Orthod Dentofac Orthop. 2004; 
27. Veli I, Ozturk MA, Uysal T. Curve of Spee and its relationship to vertical eruption of teeth among different malocclusion groups. Am J Orthod Dentofac Orthop. 2015;

28. Nayar S, Dinakarsamy V, Santhosh S. Evaluation depth of the curve of Spee in class I, class II, and class III malocclusion: A cross sectional study. J Pharm Bioallied Sci. 2015;
29. Sayar G, Oktay H. Assessment of curve of spee in different malocclusions. Eur Oral Res. 2019;

30. Al-Buraiki H, Sadowsky C, Schneider B. The effectiveness and long-term stability of overbite correction with incisor intrusion mechanics. Am J Orthod Dentofac Orthop. 2005 ; 